Int. J. Electrochem. Sci., 14 (2019) $4754-4768$

\title{
Influence of Pulse Parameters on the Morphology and Corrosion Resistance of Nickel-Graphene Composite Coating
}

\author{
Xin Yu, Ruiyu Zhang, Gan Cui, Zili Li ${ }^{*}$ \\ China University of Petroleum (East China), College of Pipeline and Civil Engineering, Qingdao \\ 266580, China \\ *E-mail: zilimenhuzu@,163.com
}

doi: $10.20964 / 2019.05 .48$

Received: 7 January 2019 / Accepted: 23 February 2019 / Published: 10 April 2019

\begin{abstract}
Ni-graphene composite coatings were electrodeposited on mild steel substrate in Watt plating solution containing suspended graphene oxide (GO). Raman spectra confirmed the reduction of GO during the deposition process. Furthermore, effects of graphene concentration and electrodeposition parameters including current density, pulse frequency, and duty cycle were investigated by electrochemical tests and various characterization techniques. Morphology and anti-corrosion properties of the Ni-graphene coatings electrodeposited under different parameters were evaluated by scanning electron microscopy, potentiodynamic polarization, and electrochemical impedance spectroscopy. The results showed that the Ni-graphene composite coating, deposited at the GO concentration of $0.2 \mathrm{~g} \cdot \mathrm{L}^{-1}$, current density of 6 $\mathrm{A} \cdot \mathrm{dm}^{-2}$, frequency of $50 \mathrm{~Hz}$, and duty cycle of 0.4 , exhibited uniform morphology and dense structure. The corrosion current density of Ni-graphene coating prepared under optimal parameters is an order of magnitude smaller than that of pure Ni coating.
\end{abstract}

Keywords: nickel-graphene, composite coating, electrodeposition parameter, corrosion resistance

\section{FULL TEXT}

(C) 2019 The Authors. Published by ESG (www.electrochemsci.org). This article is an open access article distributed under the terms and conditions of the Creative Commons Attribution license (http://creativecommons.org/licenses/by/4.0/). 